\title{
Unamuno, rector de Salamanca
}

Mariano Peset

\section{Citer ce document / Cite this document :}

Peset Mariano. Unamuno, rector de Salamanca. In: Bulletin Hispanique, tome 104, n², 2002. pp. 883-904; doi : https://doi.org/10.3406/hispa.2002.5138

https://www.persee.fr/doc/hispa_0007-4640_2002_num_104_2_5138

Fichier pdf généré le 08/05/2018 


\title{
Résumé
}

Miguel de Unamuno arrive à Salamanque comme professeur de grec en 1891. Quelques années plus tard il est nommé recteur. C'est pour lui une époque de difficultés et d'affrontements politiques. II est destitué de son poste et exilé pendant la dictature de Primo de Rivera à cause de ses articles dans $E I$ mercantil valenciano. II se réfugie en France; on rappelle son retour et ses espoirs, ses doutes devant la rébellion de Franco. . . On évoque enfin sa dernière apparition publique dans le «paraninfo » et sa dispute avec le général Millán Astray —les dernières pages qu 'il écrivit-.

\begin{abstract}
Miguel de Unamuno arrives in Salamanca in the year 1891 as a professor of Greek. Some years later he is appointed to be rector - his troubles and political struggles-. During Primo de Riveras dictatorship he was dismissed and banished because of his articles in El mercantil valenciano. He fled to France; his return and his hopes, his hesitations with regard to Francos rebellion... His last appearance at the central hall and the argument with general Millán Astray - the last pages he wrote-
\end{abstract}

\section{Resumen}

Miguel de Unamuno llega como catedrático de griego a Salamanca el año 1891. Unos años después es nombrado rector - sus dificultades y enfrentamientos políticos- . La dictadura de Primo de Rivera lo destituye y destierra por sus artículos en El mercantil valenciano. Se refugia en Francia; su vuelta y esperanzas, sus titubeos ante la rebelión de Franco. . . Su última aparición pública en el paraninfo y la disputa con el general Millán Astray —las últimas páginas que escribió-. 


\title{
Unamuno, rector de Salamanca
}

\author{
MARIANO PESET \\ Universidad de Valencia
}

Miguel de Unamuno arrive à Salamanque comme professeur de grec en 1891. Quelques années plus tard il est nommé recteur. C'est pour lui une époque de diffcultés et d'affrontements politiques. Il est destitué de son poste et exilé pendant la dictature de Primo de Rivera à cause de ses articles dans $\mathrm{El}$ mercantil valenciano. Il se réfugie en France; on rappelle son retour et ses espoirs, ses doutes devant la rébellion de Franco... On évoque enfin sa dernière apparition publique dans le "paraninfo " et sa dispute avec le général Millán Astray -les dernières pages qu'il écrivit-.

Miguel de Unamuno llega como catedrático de griego a Salamanca el año 1891. Unos años después es nombrado rector-sus dificultades y enfrentamientos politicos-. La dictadura de Primo de Rivera lo destituye y destierra por sus articulos en El mercantil valenciano. Se refugia en Francia; su vuelta y esperanzas, sus titubeos ante la rebelión de Franco... Su última aparición pública en el paraninfo y la disputa con el general Millán Astray-las últimas páginas que escribió-.

Miguel de Unamuno arrives in Salamanca in the year 1891 as a professor of Greek. Some years later he is appointed to be rector - his troubles and political struggles-. During Primo de Rivera's dictatorship he was dismissed and banished because of his articles in El mercantil valenciano. He fled to France; his return and his hopes, his hesitations with regard to Franco's rebellion... His last appearance at the central hall and the argument with general Millán Astray - the last pages he wrote-.

Mots-clés : Unamuno - Université - Salamanque - Dictature.

B. $H i ., \mathrm{n}^{\circ} 2$ - décembre 2002 - p. 883 à 904. 
BULLETIN HISPANIQUE

LA UNIVERSIDAD A FINES DEL XIX

$\mathrm{M}$ IGUEL DE UNAMUNO llegó a Salamanca un domingo de fines de junio del 1891, tomó posesión de su cátedra de griego el lunes y por la noche salió hacia Bilbao. Su primera impresión de la vieja ciudad universitaria fue buena,

Salamanca no me disgusta, unos cuantos soberbios edificios rodeados de casuchas tísicas y callejas anémicas. Yo no tengo manía a los pueblos de Castilla, se come bien en ellos y son sanos. Espero pasarlo tal cual.

Hay buenas bibliotecas y una regular consignación para adquirir libros a petición de los profesores. Mi compañero, el otro catedrático de griego, ha adquirido notables obras de griego y estudios helénicos ${ }^{1}$.

En aquellos momentos no imaginaba que pasaría su vida casi entera en esta ciudad, hasta su muerte... «iSalamanca! ¿Qué le he de decir de ella? Ha sido mi dolor y mi goce, mi vida y mi muerte. Allí he escrito mi obra, allí he engendrado mis hijos», le escribiría a Jean Cassou en 1926 desde su destierro en Hendaya ${ }^{2}$.

Le había costado obtener la cátedra: tras haber opositado a psicología, metafísica y dos veces a latín, alcanzó la de griego, ante un tribunal en que figuraban Juan Valera y Marcelino Menéndez Pelayo. Al volver en octubre repite su impresión favorable: "Este pueblo me gusta, no es tan feo como lo ponderan en Bilbao aquellos inaguantables parvenus. Hay mucha casa nueva y se conoce que lo están mejorando. He visitado ya la catedral, Santo Domingo, etc., y seguiré viendo lo que haya... Según parece a esta Universidad todo se le va en comisiones, misas, mascaradas y ceremonias». Pronto se adaptaría al ambiente, "nos vamos haciendo a este pueblo, que me gusta. Me intereso en sus menudencias y luchas de campanario, conozco a sus tipos, tipejos y calabazas, he empezado a hacerme sitio en él, encuentro buenos amigos y gentes con quienes hablar y todo va bien" ${ }^{3}$. En aquellos años estaba

1. Carta a Mugica 18 de julio de 1891, Cartas inéditas de Unamuno, recopilación de S. Fernández Larraín, 2a edición, Zig-Zag-Rodas, Madrid, 1972, p. 135.

2. Sobre el rector vasco: Manuel García Blanco, En torno a Unamuno, Tecnos, Madrid, 1965, p. 611, así como las Obras completas de Unamuno, que preparó, 16 vols., Afrodisio Aguado, Madrid, 1958-1964; Emilio Salcedo, Vida de don Miguel, 2a edición corregida, Anaya, Madrid, 1970; Valentín del Arco López, "El siglo XX: 1900-1936», La universidad de Salamanca, 3 vols., Universidad de Salamanca, 1989, I, p. 229-286.

3. Cartas a Mugica de 4 de octubre y 23 de noviembre de 1891 , Cartas inéditas, p. 139 y 141. Sobre su oposición hay varias referencias, Mugica le remitió unos libros que le pedía para un ejercicio, p. 131-132. 
enfrascado en la recogida de materiales y redacción de su novela histórica Paz en la guerra (1897), sobre el sitio de Bilbao en la última guerra carlista. Prepara sus clases, examina, incluso a los que vienen de Deusto -considera los exámenes la mayor de las farsas-. Se siente socialista, escribe en los periódicos - para ganar algo más- ${ }^{4}$, traduce, se interesa por la lengua castellana, nacen sus hijos, pasea una hora todos los días... Años después rememoraría con afecto la universidad de hacía veinte años, que era la misma de hace cincuenta y tres, en la que él estudió. Era una oficina del Estado, esas monsergas de la alta cultura vinieron después. Era continuación del bachillerato, para uso de la burguesía pequeña y grande. De corporación nada tenía, sólo se congregaban en la apertura y en el claustro, para algunas chinchorrerías... Cada profesor cumplía según su conciencia; su majestad el catedrático explicaba o leía algún manual costoso o algunos apuntes. Algunos despertaban vocaciones, aunque había mucho autodidacta. Los exámenes eran el centro de la mala vida universitaria... Luego vino la alta cultura y los investigacionistas, que a veces improvisan publicaciones para que les valgan en concursos y oposiciones. "No creo que cuando se haga el proceso de instituciones sociales y categorías sociales públicas que han contribuido a la formación de la actual civilización española quede la obra de aquella modesta universidad, que tiraba a formar facultativos de profesiones liberales, por debajo de las otras» 5 .

Era rector entonces Mamés Esperabé desde 1869. Era un hombre progresista, partidario del exaltado Ruiz Zorrilla, ministro de fomento en los inicios de la gloriosa revolución que poco pudo hacer por la universidad, de que sólo quedaron algunas órdenes ministeriales, algún proyecto... Fueron tiempos muy difíciles con la abdicación de Amadeo de Saboya y la primera república -Esperabé votó como senador de Palencia su advenimiento-, con levantamientos cantonales y carlistas... Cuando, tras el pronunciamiento de Martínez Campos en Sagunto se restaura la dinastía con Alfonso XII, el rector revolucionario decidió no dimitir, y fue respaldado por gobiernos conservadores y liberales hasta fin de siglo. Alguna vez quiso destituirlo un ministro de fomento, el integrista Pidal, pero se opuso el presidente del gobierno conservador, Cánovas del Castillo. Fue persona discreta y tolerante, que procuró contentar a todos durante su

4. Escritos socialistas: artículos inéditos sobre el socialismo 1894-1922, edición de P. de Ribas, Madrid, Ayuso, 1976.

5. «La universidad hace veinte años», Obras, X, p. 985-990; rememoraría sus pugnas con integristas, carlistas, neos... «Recuerdos vivos», X, p. 995-998. 
rectorado... ${ }^{6}$. Había llegado en 1863 a la cátedra de griego por concurso desde el instituto de Málaga. Ya en el siguiente curso pronunció el discurso de apertura, una pieza oratoria, al gusto de aquellos años ${ }^{7}$. Fue nombrado rector por la junta revolucionaria local, y confirmado por el ministerio en octubre de 1869. Se mantuvo mucho tiempo, lo respetaron conservadores y liberales, como gran conocedor del mundo universitario, que pretendió reformar a través de memorias bastante retóricas que presentó al gobierno...

La universidad de Salamanca, de tan prestigiosa historia, había sufrido grave disminución en los años liberales. Todavía conservaba su prestigio durante los reinados de Carlos IV y Fernando VII, aunque la represión absolutista acentuó la decadencia de todas. Los liberales, en cambio, centralizaron y concentraron en Madrid las enseñanzas más completas, el doctorado, las oposiciones... Salamanca perdió la facultad de medicina, y filosofía y letras quedó limitada a unas cuantas cátedras previas para los estudios de derecho... La supresión de teología -sus estudiantes pasaron a los seminarios- por la revolución del 68, dejó la universidad del Tormes reducida a la facultad de derecho. Juan Valera defendió en el congreso su pervivencia, con argumentos basados en la atracción de portugueses, y en pro de un iberismo, vivo en aquellos años... Tan sólo un ministro, el conservador marqués de Orovio tuvo cierta sensibilidad y quiso concederle un estatuto especial. Orovio, integrista, había provocado la primera cuestión universitaria en 1865 -la llamada noche de San Daniel-, el primer atentado directo contra la mínima libertad de cátedra ${ }^{8}$. Emilio Castelar había escrito un artículo - «El rasgo»-, donde ironizaba y reprochaba a la reina que, al ceder el patrimonio real al estado, se había reservado un veinticinco por ciento. Fue destituido de su cátedra y los estudiantes de Madrid prepararon una serenata en su apoyo, que degeneró en enfrentamientos con la guardia civil y dio lugar a fuerte represión gubernativa. Sáinz del Río, Fernando de

6. José $M^{a}$ Hernández Díaz, La universidad de Salamanca, I, p. 213-227; Enrique Esperabé de Arteaga, Historia pragmática de la universidad de Salamanca, 2 vols., Salamanca, 1914-1917, le dedica muchas páginas del volumen segundo; reproduce Homenaje. Revista consagrada a honrar la memoria del rector Mamés Esperabé Lozano en el primer aniversario de su muerte, Salamanca, Núñez, 1907; E. Pinto Sánchez, Datos biográficos de don Mamés Esperabé Lozano rector que fue de la universidad de Salamanca, Plasencia, La Minerva, 1907.

7. I. a unidad, no la contradicción es la ley fundamental de los sucesos y los conocimientos humanos, Salamanca, Imprenta de Diego Vázquez, 1865.

8. Mariano y José Luis Peset, La universidad española (siglos XVIII y XIX). Despotismo ilustrado y revolución liberal, Madrid, Taurus, 1974, p. 753-763; Paloma Rupérez, La cuestión universitaria y la Noche de San Daniel, Madrid, 1975. 
Castro y otros catedráticos krausistas perdieron sus cátedras. En 1875, de nuevo en el ministerio, Orovio exigió que presentaran programas y no explicasen contra la fe, a que no se prestaron unos treinta profesores, con Francisco Giner de los Ríos a la cabeza. La razón eran las explicaciones relacionadas con Darwin y la descendencia del mono... 9. Abandonaron la cátedra y fundaron la Institución libre de enseñanza: fueron repuestos en 1881 en el primer gobierno de los liberales de Sagasta... Sólo un ministro como Orovio podía interesarse por Salamanca, que parecía condenada como representación del antiguo régimen, del clericalismo y el atraso...

Con el rector Esperabé empezó a recuperarse aquella vieja universidad que tantas postergaciones había sufrido -apenas quedaban rastros de su grandeza-. Tal vez porque representaba el antiguo régimen, el conservadurismo de sus facultades de teología, desaparecida, y derecho. Durante su mandato de treinta años el rector reparó los edificios universitarios -los relieves de la escalera, el artesonado, el paraninfo, la capilla...-, y amplió la biblioteca y otras dependencias. Celebró el centenario del descubrimiento de América y de Calderón, y levantó una estatua a fray Luis de León: logró que Salamanca tuviera presencia en fastos políticoculturales. Intervino para que los restos de Meléndez Valdés volvieran de Francia a Madrid... Y, sobre todo, logró la creación de secciones de historia y literatura en filosofía y letras, y las facultades libres de medicina y ciencias, costeadas por la diputación y el ayuntamiento. Salamanca empezaba a levantarse. Era además un buen gestor, consiguió subvenciones y se esforzó por recuperar láminas de deuda pública que le correspondían, negándose a entregarlas pese a varios requerimientos del gobierno. La supresión de diezmos y la desamortización había destruido las rentas y el patrimonio, sólo le quedaba aquel papel del Estado, depreciado. Creó becas, cuando todavía no se concedían por el gobierno... Políticamente se mantuvo como liberal, enfrentado a los obispos y a los neos o integristas, aunque abierto a todos. En las elecciones de senador apoyó a Valera y a otros liberales, frente a propuestas respaldadas por el poder y la iglesia -en una ocasión se le quiso impedir entrar en la catedral por los canónigos-- Desde luego, mantuvo su autoridad frente a condenas de la iglesia y una parte del claustro contra el penalista Pedro Dorado Montero, lombrosiano y krausista... Durante su rectorado se

9. Julio Caro Baroja, «I. "El miedo al mono" o la causa directa de la "cuestión universitaria", en 1875. - II. Algunas noticias más sobre el origen de la "cuestión universitaria" (1876)", En el centenario de la institución libre de enseñanza, Madrid, 1977, p. 23-41. 
respira un aire algo más abierto: en algún discurso de apertura un jurista habla de Comte o de Darwin, aunque sea de segunda mano. En la restauración otro profesor defiende la libertad de cátedra... ${ }^{10}$.

Cuando murió se organizó un homenaje en que participaron muchas personas. A través de algunos de estos escritos se revela la aceptación que gozaba entre hombres de las tendencias más encontradas. Unamuno, como rector, subrayaba su progresismo, entibiado con los años, su liberalismo indudable y tolerancia. Benito y Endara, de derecho mercantil, afirma su carácter enérgico y a la vez de amigo y padre para todos. Mientras, el conservador Gil Robles, de derecho constitucional, ensalza su amor a las tradiciones de la escuela. Disculpa su primera formación, porque entonces el pensamiento moderno era fatalista y anticristiano, aunque en lo más recóndito de aquellos hombres ardiera la fe... Por ello el rector se prosternaba con la más sincera piedad y la más tierna devoción ante Jesucristo sacramentado, como en los mejores días de aquellos varones, gloria de la escuela, fieles siempre al divino Libertador; "...en él se mantuvo invicta la tradición capital y salvadora de la raza, de la Patria y de la Escuela, la fe inquebrantable, la amorosa y segura esperanza en el Rey inmortal de los siglos» ${ }^{11}$. Cada uno veía en el difunto sus propias creencias e ideología; aparte su tolerancia, la persistencia en el mando le confirieron una posición por encima de todos...

Unamuno se encontraba a gusto en la vieja universidad. En 1898 se produce la guerra con Estados Unidos y la pérdida de las últimas colonias... Como a muchos, que todavía creían en el porvenir de España, los acontecimientos le producen intensa desazón, cada día era peor la situación política: «La ingénita soberbia española y el espíritu sanguinario y terco que nos distingue están produciendo sus frutos», escribe a Mugica. Cuando llegó el desastre varios catedráticos -Rafael Altamira, Bartolomé Cossío, Francisco Giner...- publicaron sobre los males y remedios de la universidad. Unamuno envió ocho artículos a la Revista nueva, que publicó además como

10. Discurso leido... en la solemne apertura del curso 1871 a 1872 por el doctor don Ricardo Cid..., Salamanca, Sebastián Cerezo, 1871. Sobre Dorado véase Ignacio Berdugo Gómez de la Torre, Benigno Hernández Montes, Enfrentamiento del padre Cámara con Dorado Montero, Salamanca, Diputación provincial, 1984; J. Ma Hernández Díaz, "Pedro Dorado Montero y la educación", Historia de la educación, 2, 1983, 217-227; Mariano y Rafael Peset, "Positivismo y ciencia positiva en médicos y juristas del siglo XIX: Pedro Dorado Montero", Almena, 2, 1963, 65-126.

11. Enrique Espérabe de Arteaga, Historia, II, p. 162-163. 
libro aparte ${ }^{12}$. Intentaba elevar la moral: si queremos que España subsista como pueblo vivo, hemos de hacer patria, lo que exige un ideal de vida, una misión que cumplir, una fe, cualquiera que sea... ¿Cuál puede ser el oficio de la universidad en este hacer patria? Desde luego no en el ejército o con la bandera que ondea en el cruento combate; no hay que morir por la patria, sino vivir por ella. Hay que enseñar el heroísmo del trabajo y el culto a la verdad. "Nuestra mayor gloria será renegar de muchas de nuestras glorias, entre ellas de las más recientes». Unos cuantos sabios hacen más por la patria que los batallones. Su crítica de la universidad es acerba: los exámenes, que nada enseñan, son amarguras, memorismo de repetición de un manual. La ciencia no es algo mágico que se enseña, sino un hambre de saber, un espíritu, no unos títulos... La juventud se cansa pronto, porque le dan el gato ya cazado y aderezado... Todo es dogmatismo, la asignatura está determinada, toda ordenada, enjaulada; hay que darla completa, siempre falta tiempo. O se pide, a veces, "refútese... tal o cual cosa", o díganse los «funestos resultados de la revolución francesa». Se ordenan como tesis, argumentos y conclusión -como en teología-. Otras veces se contentan con unas cuantas definiciones y las opiniones de unos y otros. Soluciones, pereza mental, fórmulas, simplificaciones, extravagancias... El resultado es la incultura, la ignorancia que algunos profesores estimulan. Es una oficina, en donde se dan clases, se endilga la lección y ya es domingo para el resto del día. Algunos catedráticos apenas leen; hay muchos incapaces de leer de corrido salvo el castellano. Si alguno medita sobre su asignatura, le dicen que enseña antropología o sociología, no derecho penal -alude a Dorado Montero-. No existen claustros, ni vida corporativa, el ministro no consulta nada -desde que es catedrático, en ocho años, una vez sobre disciplina-. No hace falta que el ministro reforme los planes, mientras no cambien quienes han de explicar y enseñar, sólo el espíritu y la amplitud de alma hacen buena una reforma. Mejor es no variar, "de ese tejer y destejer desde el ministerio la tela de Penélope de nuestra enseñanza oficial, nadie hace caso. Cada ministro trae su receta, cambia las etiquetas de los frascos y el lugar de colocación de algunos...» ${ }^{13}$. Otra manía es la práctica, pues se dice que la última derrota se debe a que teníamos más teorías que los americanos. Basta de

12. Miguel de Unamunò, De la enseñanza superior en España, Madrid, Revista nueva, 1899, a que añadió otro anterior sobre el latín, aparecido en 1894 en La España moderna. Obras, III, p. 55-119; también habla de docencia en su conferencia en el ateneo de 1899, "Nicodemo el fariseo», 121-153.

13. De la enseñanza, p. 41 . 
teorías...jComo si la aplicación pudiera hacerse sin teoría! La mayor utilidad de las universidades es el cultivo de la ciencia pura... También es manía actual la especialización: el desenvolvimiento de las ciencias requiere especialistas, pero hay que tener una visión amplia, filosófica. El que es un remachador de cabezas de alfiler, aunque reúna tantos hechos y noticias como Darwin, no se le ocurre la evolución. Los progresos los traen los filósofos de una ciencia, los bárbaros de fuera de ella... Es verdad que en España hay mucho generalismo, pero falta filosofía ${ }^{14}$. Años más tarde vendrá Ortega con sus minorías y masas, contra el bárbaro especializado. Unamuno literato y además pensador- se refería a algo distinto: el estado de la ciencia en España, el desafío que suponía un pueblo analfabeto, una incultura generalizada, exigía la dedicación a otro tipo de tareas, no a la erudición y el especialismo... En la apertura del curso de 1900 pronunció el discurso, animando a los estudiantes a despertar el ideal dormido, a conocer el pueblo, a que estudien no sólo en los libros sino en la realidad viva, intuida, con imaginación - «ojos y oídos bien abiertos»-. A entender la teoría que fundamenta la acción, no la escolástica ${ }^{15}$.

\section{PRIMER RECTORADO}

Aquel año sería nombrado rector por jubilación de Esperabé, al cumplir 70 años. Se recogieron firmas para que volviese, incluso la de Unamuno. Tomó posesión en un aula, sin solemnidades; pero al salir los estudiantes lo llevaron al paraninfo donde pronunció unas palabras...

García Alix -ministro del gobierno conservador de Silvela- intentó cambios desde el ambiente de regeneración que se vivía. Fue el primer ministro de instrucción pública y bellas artes y se aplicó a mejorar la disciplina y controlar los programas, rehizo los planes y restauró el examen de ingreso a la universidad, varió la selección del profesorado... Los remedios usuales de los ministerios desde hacía décadas. Pero también propuso una ley de organización de las universidades, que concedía una mínima autonomía, la elección del rector en terna por el claustro, algunas rentas afectadas a la universidad... poco más. El ministro liberal Romanones, que le sucedió pronto por un cambio de gobierno, mantuvo el proyecto, aunque

14. Véase «Sobre la erudición y la crítica», Obras, III, p. 902-925. También en las cartas a Mugica insiste en esta actitud.

15. Obras, VII, p. 493-504. 
parece que él mismo procuró hundirlo ${ }^{16}$. En el primer claustro de Salamanca que preside Unamuno se debate la nueva ley y se aprueba la ponencia que había preparado Gil Robles. A partir de este momento las universidades reclamaron autonomía en varias reuniones, iniciadas en Valencia en 1902, con motivo de la celebración del IV centenario, para forzar al ministerio a mejorar las universidades y concederles mayor poder a los claustros. Se congregaron de nucvo en Barcelona 1905, Madrid 1915... Sin embargo, el rector Unamuno tenía sus reservas: no es la autonomía universitaria, "lo que habrá de vivificar la docencia (pudiera ser que la empeorara), sino que es vivificándola primero como se ha de merecer aquélla" ${ }^{17}$. Contrapone las antiguas universidades a las actuales que son oficinas del estado; pide que sean animadas por algún espíritu, sin necesidad de cambiar la ley externa. No sólo deben dispensar ciencia, sino hacerla, fraguarla.

Había sido nombrado rector por la jubilación forzosa de Esperabé, introducida por García Alix, por vez primera en la universidad española. Tras el largo y brillante rectorado anterior le aguardaba difícil tarea. Se mantuvo años, aunque muchos profesores y otras fuerzas vivas lo rechazaban... La primera cuestión se planteó porque el ministro quería suprimir las facultades libres de medicina y ciencias. Una comisión, encabezada por un senador y el obispo Cámara, con orras autoridades, logra parar el golpe. Cae el ministro, y su sucesor Romanones no tiene inconveniente en prolongar la vida de aquellas facultades que no paga el ministerio. Una manifestación de escolares a favor de la pervivencia de las facultades, se enfrenta al rector porque no les presta las banderas de la universidad... La presencia de Romanones en la apertura de 1901 fue acogida con gran entusiasmo, con arco de triunfo y todo... Sus palabras son pura retórica política sobre la tradición salmantina y la buena voluntad del ministerio para la "difusión de las luces de la enseñanza», sobre sus propias realizaciones y proyectos, también se niega a ser tenido por enemigo de la iglesia ${ }^{18}$.

16. Sobre estas reformas, Mariano Peset, «Política universitaria tras el desastre del 98", Las universidades hispánicas, Universidad de Salamanca, 2000, II, p. 425-447; Yolanda Blasco, La facultad de derecho de Valencia durante la restauración, Universitat de València, 2000, p. 77 106.

17. La ponencia que envió a Barcelona en 1905, "La enseñanza universitaria», Obras, VII, p. 613-623, cita en 614. Véase, José Carlos Mainer, "La redención de los paraninfos: asambleas y regeneracionismo universitario", La crisis del Estado español, 1898-1936, Madrid, 1978, p. 213-244.

18. Discurso leido en la universidad de Salamanca por el ministro... Excmo. Sr. Conde de Romanones, Madrid, R. Romero, 1902. Se produjo un desfalco que tuvo que solucionar 
Fue peor el 1903: ante los malos tratos a un escolar en la plaza mayor, la asociación de estudiantes, con su líder Filiberto Villalobos, desencadena protestas. Unamuno quiere proteger a los estudiantes, la guardia civil entra en la universidad y dispara, también en la calle Libreros, dos muertos y varios heridos... En la apertura de 1904 asiste el monarca -discursos protocolarios-. Unamuno evoca a su padre Alfonso XII y solicita su protección... ${ }^{19}$. Algo después el rector entregaba las láminas de deuda pública, conseguidas y conservadas con celo durante años por don Mamés. De nuevo entraría en contradicción con sus oponentes, entre los que destacaba el hijo de Esperabé, catedrático de griego como su padre. Al año siguiente hay manifestaciones estudiantiles contra el rector, por no querer entregar otros edificios al batallón Albuera, que no cabe en el trilingüe -si se trasladaba el cuartel perjudicaría al comercio, tendrían que hacer fuera el servicio militar-.

Su discurso en el teatro de la Zarzuela de Madrid -en la época en que se está gestando la ley de jurisdicciones que daba entrada a los militares en el mantenimiento del orden civil- no es un alegato político, sino una llamada al patriotismo, a la revolución interior, ni desde arriba ni desde abajo... Aborda el militarismo, pero todavía cree que el ejército convive con el pueblo y posee cierto grado de cultura... ${ }^{20}$. Sigue en buenos términos con el gobierno, incluso corrían rumores de que iba para ministro... Condenaría a Ferrer Guardia, el anarquista fusilado en Barcelona, hecho responsable de la semana trágica de 1909; aunque años más tarde rectifica. Escribe mucho, estrena alguna obra de teatro, polemiza...

Unamuno, a pesar de los cambios de gobierno, se mantiene en el rectorado hasta 1914; repentinamente es cesado por el ministro de instrucción pública Bergamín con ocasión de una elección de senador, en

Unamuno, E. Salcedo, Vida..., p. 122-123. Como rector expuso en Madrid ante el joven rey una síntesis de la historia de la universidad, y petición de que se mantengan por el Estado, Obras, VII, p. 518-524.

19. Sobre asociaciones estudiantiles, José $M^{2}$ Hernández Díaz, «La condición de los estudiantes de Salamanca en el umbral del siglo XIX», Educación y sociedad. Perspectivas históricas, 2 vols., Salamanca, 1985, II, p. 336-349; Antonio Rodríguez de las Heras, Filiberto Villalobos: su obra social y politica (1900-1936), Salamanca, 1985. Sobre la regia visita, Memoria sobre el estado de la instrucción..., Salamanca, Francisco Núñez, 1904, p. 49-52.

20. Obras, VII, p. 658-680; también "La patria y el ejército", III, 974-991, glosa su actuación años más tarde, "Pequeña confesión cínica», VII, 11-14. Sobre Ferrer, I, 588-597 y X, 393-396, véase B. Delgado, Unamuno educador, Madrid, Magisterio español, 1973, p. 107-133. 
que no quiso ser candidato y la perdió el propuesto desde el ministerio -también le culpan rumores de irregularidad administrativa...-. La injusticia de sustituirlo sin motivo concreto, llegó hasta las cortes. Reclamaron al ministro Bergamín, en el congreso Marcelino Domingo -ministro después en la república- y Luis Maldonado, senador por la universidad de Salamanca en la cámara alta; éste le reprochaba que quería sujetar a la universidad al caciquismo local y las banderías electorales: "los ministros pasan y las universidades quedan -le decía-, y de los hechos de su señoría al cabo de los años, allá por el siglo XXIII, cuando se escriba la historia de la universidad de Salamanca y de Unamuno, apenas si quedará algún resto...» ${ }^{21}$. El claustro se reúne para expresar su sentimiento por el cese, al tiempo que el júbilo por la designación del vicerrector Cuesta y Martín como rector. Unamuno quiere hablar, pero Cuesta no le deja, se sale de la reunión... Fue nombrado vicerrector Enrique Esperabé de Artega, hijo del anterior rector, enfrentado con el vasco. Dos años después el claustro de filosofía lo propone como decano, pero no acepta. Durante unos años se aísla de la universidad.

El 21 de noviembre de 1914 había expuesto lo que debe ser un rector, en el ateneo de Madrid, se defiende de su destitución sin causa. No es un cargo de confianza, como un gobernador -dice-, más bien se asemeja al presidente del Instituto de reformas sociales o de la Junta para ampliación de estudios. Debe cumplir con escrúpulo la ley, como él hizo, que restringió licencias y jubiló mediante expedientes de capacidad a quienes no debían enseñar. Las universidades son «miserables fábricas de licenciados y colegios electorales de senadores» 22 . Los profesores sólo se preocupan del escalafón, los manuales y las vacaciones. Aunque la autonomía sería un desastre, pues se introduciría un índice inquisitorial en las bibliotecas y saldrían catedráticos los yernos, hijos y sobrinos de los existentes, como pasó con los premios. El caciquismo impera en el consejo de instrucción pública, pero la oposición es solución menos mala que el arbitrio ministerial... Pide más bien una legislación más moderna, adaptada al presente, más flexible, menos casuística, que limite la irresponsabilidad de los catedráticos y los poderes arbitrarios del ministerio.

21. Manuel García Blanco, En torno..., p. 157-161.

22. "Lo que ha de ser un rector en España», Obras, VII, p. 853-883; véase también "Autonomía docente" y "Conferencia pronunciada en la sesión pública del 3 de enero de 1917, en la real academia de jurisprudencia y legislación de Madrid», VII, 921-925 y 931938. 
Con el paso del tiempo su postura se radicaliza, adopta actitudes más políticas y resueltas, un distanciamiento con Alfonso XIII y sus gobiernos. Escribe sobre la gran guerra, participa en el mitin de 1917 en la plaza de toros de Madrid con los republicanos: Simarro, Albornoz, Melquiades Álvarez, Lerroux... Cuando el comité de la huelga sale de prisión-Besteiro, Largo Caballero- publica páginas en las que alude al rey. Se le tributa un homenaje, y Romanones desde el ministerio parece que quiere congraciarse, como también su sucesor Burell...

En 1919 se promulga un decreto de autonomía de las universidades por César Silió, ministro de instrucción en el gobierno conservador de Antonio Maura. Se daban algunos pasos indudables: elección del rector por el claustro de catedráticos, fortalecía las decisiones colectivas, asignaba patrimonio y rentas; dos miembros de la facultad de cinco en los tribunales de oposiciones -que se realizarían en cada centro-. En Salamanca fue bien recibido el decreto y aquel verano trabajaron los claustros en la redacción de su estatuto: significaba un cambio de modelo que todavía tardaría en llegar más de medio siglo. Su amigo el rector Luis Maldonado se dirige a Unamuno para que colabore y ponga fin a su aislamiento. El estatuto salmantino se aprobó entre los últimos, el 19 de octubre, sólo Barcelona y Madrid fueron posteriores. Los diversos estatutos son bastante semejantes, dentro del marco concedido: la elección de rector y vicerrector por el claustro estaba determinada en el decreto; Salamanca exigió que estuviera en activo, y sólo podría ser nombrado rector honorario quien hubiera desempeñado antes ese cargo -sin duda pensaban desagraviar a Unamuno-. Eran órganos de decisión los claustros ordinarios de catedráticos y la comisión ejecutiva que ayudaba al rector, mientras apenas tenía competencias el claustro extraordinario de todos los doctores -salvo su vieja función de elegir un senador cada universidad-; como tampoco lograban fuerza las asociaciones de estudiantes, ni la asamblea general, reunión de todos los órganos colegiados. El estatuto de Salamanca no se distinguió por aportar novedades, como se perciben, tímidas, en los de Madrid o Barcelona ${ }^{23}$.

En septiembre de 1920 con ocasión de un artículo en El mercantil valenciano se le incoa a Unamuno causa ante los tribunales de Valencia, por

23. Mariano Peset, Ma Fernanda Mancebo, «Un intento de autonomía universitaria: el fracaso de la reforma Silió de 1919», Homenaje a Juan B. Vallet de Goytisolo, Madrid, Consejo general del notariado, 1990, VI, p. 507-557; Valentín del Arco López, «El siglo XX: 19001936", p. 246-251; Manuel García Blanco, En torno..., p. 161-166. El estatuto de Salamanca, como los demás, puede verse en El nuevo régimen de autonomía universitaria. Extracto de documentos, Ministerio de instrucción pública y bellas artes, Madrid, 1919. 
injurias a la corona y es condenado a dieciséis años; el republicano Ossorio y Gallardo, su abogado, recurre al supremo... Simarro inicia una campaña en su defensa. Hasta el claustro de Salamanca eleva una protesta: el vicerrector Esperabé de Arteaga se ve obligado a cursarla. Unamuno se presenta a diputado republicano por Bilbao y con los socialistas por Madrid, aunque sin éxito... En 1921 fue elegido decano de letras, y en enero vicerrector a propuesta del claustro, con Maldonado de rector. "Al cabo de siete años y medio vuelvo a este melancólico despacho de la rectoral de la vieja Universidad de Salamanca, a este rinconcito recatado y triste, siempre en penumbra, a esta celda donde tan intensas horas viví y tan duras campañas planeé e inicié. Es un cuartito pequeño, una verdadera celda monacal» ${ }^{24}$. La ausencia del rector Maldonado -senador y político- lo lleva a intervenir en los varios problemas existentes entre la facultad de medicina y el hospital. Sigue reticente con el monarca, y una visita a palacio no rompe la tensión... En octubre los reyes presiden la apertura de curso en Salamanca, con la canonización y doctorado de Teresa de Ávila -Unamuno no está presente, se excusa-. Meses después dimite Maldonado -y en consecuencia su vicerrector Unamuno-, y es nombrado rector Esperabé de Arteaga.

\section{LA PRIMERA DICTADURA MILITAR}

En septiembre de 1923 Primo de Rivera se pronuncia en Barcelona, el rey acepta y se suspende la constitución. Se forma un directorio militar, después sustituido por otro de civiles. En diciembre Unamuno comparece ante un tribunal en Valencia para responder por injurias a la magistratura: fue absuelto. Unos artículos en El mercantil valenciano de 19 y 20 de febrero - una carta indiscreta que se publica en Buenos Aires- provocaron la cólera de Primo. Unamuno se unía a la prensa de Madrid, que pedía levantar la censura previa, contraproducente; en primer lugar, porque es difícil hallar censores equitativos- nadie lo hace por vocación o gusto-, no se inclinan a la lenidad, porque tienden a satisfacer el parecer de sus superiores. Un ejemplo, había enviado un artículo al semanario España y fue tachado entero por la censura, en cambio lo editó sin problema otro semanario Nuevo mundo. Corren además hojas clandestinas, o se publica en el exterior lo que se debe lavar en casa. Ataca el pronunciamiento de Barcelona:

24. "La mosca bicentenaria», Obras, X, p. 504-509. Sobre las candidaturas de 1920 escribió «Diario de un azulado», Obras, X, p. 465-496. 
Los políticos del antiguo régimen... ¡Pero no del régimen, porque el régimen, el que hemos llamado siempre el régimen, el monárquico tradicional, es el mismo, y no sabemos que España cambiara de régimen el 13 de septiembre de 1923. Y nos parece que a los que está preparando el terreno el Directorio no es a políticos de un nuevo régimen, sino a nuevos políticos del régimen. Por lo cual cuando con evidente ligereza se habla del nuevo régimen, contestamos que no vemos la novedad. Y si no creyéramos ir acaso a perder el tiempo y el trabajo, por obra de la censura a los censores, explicaríamos esto de que no vemos la novedad ${ }^{25}$.

Sin duda no le agradaba a Primo de Rivera la suelta pluma del catedrático. El día 20 -con su firma de Ángel Guerra- aparece «Punto de arranque», sobre Cánovas y su promesa tras el golpe de Sagunto de continuar la historia de España, a la vez que historió su decadencia bajo los Austrias; sin duda se había ahondado el declive y desmoronado con Felipe $\mathrm{V}$ y los Borbones, expulsados de los países europeos, de las plazas africanas de soberanía - ¿alude a la derrota de Annual, que se atribuyó a una orden de Alfonso XIII?-, de América... Portugal sigue separado "¿Era acaso esa historia la que venía a continuar Cánovas del Castillo a tenor de su frase solemne? No la explicó nunca. Pero desde luego se advierte la gran contradicción que se ofrece entre las severidades del historiador que desentraña los orígenes de nuestra decadencia y las devociones del político al servicio de ideales que no podían inspirarle ni confianza ni fe».

En aquel periódico republicano había publicado antes algunas páginas intencionadas. El 20 de enero, «Un deber de la iglesia», desde Bilbao, donde muchos fanáticos contrarios al separatismo quieren que se condene por la iglesia. "El separatismo podrá ser un crimen de Estado -y ello depende de los medios de que se valga-, pero no es un pecado. Ni sabemos que haya energúmeno que se atreva a declarar que el separatismo es pecado, como don Félix Sardá y Salvany declaró que lo es el liberalismo". El día 8 de febrero apareció «Ánimo mostrenco», en que comentando a Aristóteles, refería que Solón castigaba a quienes no se decidían por un bando: «Sin partidos políticos, como sin opinión pública no es posible gobernar normalmente», no hay gobiernos apolíticos, sin discordias no hay grandeza de la

25. El mercantil valenciano, 19 y 20 de febrero de 1924, primera plana. El ejemplo que da se refiere a «Un deber de la iglesia», aparecido también en este periódico el 20 de enero. Se instruyeron diligencias por la jurisdicción militar por su conferencia en El Sitio, carta de Indalecio Prieto de 14 de enero, D. Molleda, El socialismo español y los intelectuales. Cartas de líderes del movimiento obrero a Miguel de Unamuno, Universidad de Salamanca, 1980, p. 502. Por estas fechas prefiere no afiliarse al partido socialista. 
patria. Puede haber gobiernos de concentración, llamados nacionales, pero a partir de septiembre pasado ya no serán posibles. Es una tregua, un interregno del liberalismo, «Y volverá, ¡vaya si volverá!, el viejo, no el viejo, sino el eterno liberalismo, el de hace un siglo, el glorioso constitucionalismo de tiempos de Riego... Lo que hay que hacer es repristinarlo, devolverle su antiguo espíritu, aquel espíritu que se le quitó en $1876 \ldots$... Y acababa,

La civilización, la cultura, la libertad, la justicia sólo viven por la política y con la política, y la política no vive sino de las discordias civiles y gracias a ellas. Solón veía claro ¡Y si hay unanimidad en un pueblo! ¿ Unanimidad? La unanimidad sólo es posible entre imbéciles, es decir entre gentes que no tienen ánimo. Porque un ánimo mostrenco no es tal ánimo. Es inanimado o exánime ${ }^{26}$.

En «Socialistas y republicanos» afirmaba "que nunca ha habido en España más republicanos que ahora los hay», inciso que, con algún otro, tachó la censura en su edición en El socialista, según le comunica Andrés Saborit y Fernando de los Ríos, "como no dejan blancos pusimos unos puntos donde faltaba algo para orientar a los lectores avisados, que en estas épocas deben serlo todos» 27.

El dictador reacciona duramente ante las críticas y alusiones, y lo destierra a Fuerteventura -junto al republicano Rodrigo Soriano-, a la vez que cierra el ateneo de Madrid por su política "estridente y perturbadora». Considera que "no es tolerable que un catedrático, ausentándose continuamente de su cátedra y fuera de su misión, ande haciendo propagandas disolventes y desacreditando de continuo a los representantes del Gobierno y al propio Soberano, que tan benévola y noble acogida le dispensó en su palacio" ${ }^{28}$. La Gaceta publicó la correspondiente orden de 20 de febrero de 1924 con el cese de vicerrector y decano de letras, suspensión de empleo y sueldo y destierro. El 4 de julio se le concedió amnistía, pero sin reponerlo en la cátedra -había huido a París-. El directorio escribiría a la universidad,

26. El mercantil valenciano, 20 de enero y 8 de febrero de 1924, primera plana. Hay varios artículos suyos, firmados Ángel Guerra, más dedicados a libros y temas literarios, aunque alguno contiene cierta ironía, 9, 15, 24, 26 -sobre los grandes de España y su derecho de cobertura y su protocolo, con los versos de Jorge Manrique, "Los infantes de Aragón, qué se hicieron?»...-, 30 de enero, un dictador de Paraguay, y 1, 4, 6, 11 de febrero.

27. El mercantil valenciano, 13 de febrero, véase D. Molleda, Los intelectuales..., p. 537.

28. Nota oficiosa y orden aparecen en El Sol de 22 de febrero de 1922, Fernando Díaz Plaja, La historia de España en sus documentos. Dictadura... República (1923-1936), Instituto de estudios políticos, Madrid, 1964, p. 33-35. Da cuenta El mercantil valenciano del día 22: se enteró Unamuno por una noticia en un tablón de prensa en la plaza mayor, luego le llegó la notificación. 
para que le formase expediente por ausencia y lo privase de la cátedra. Unamuno le dirigió un escrito, en que narraba los hechos y reafirmaba su actitud:

El día 8 de julio pude evadirme del confinamiento, merced a la generosidad de la noble y civilizada nación francesa, que me ofreció aquí asilo, libertad civil, respeto y dignidad. Que he sabido que el día 4 del mismo mes de julio se había firmado un decreto real mal llamado de amnistía y que, aunque no podía alcanzarme, pues que no había de qué amnistiarme por no haber ni inculpación siquiera, se me permitía por él salir libremente del confinamiento en que sin causa ni motivo declarado -lo repito- se me tenía; pero que yo tenía, como sigo teniendo razones para no volver a España, donde hoy no podría residir personalmente seguro, ni con dignidad moral, ya que hay que vivir actualmente en ella fuera de todo régimen moral de justicia, sin garantía jurídica de ningún género y a merced de la violencia arbitraria de cualquier loco revestido de autoridad o agente de ella ${ }^{29}$.

A continuación expone sus razones, ¿cómo podía acudir a su cátedra si lo habían suspendido de su empleo por orden del rey? Pide que se le reintegre en justicia -no por amnistía-, con los haberes desde el día que se le retiraron. No se dio curso a su escrito, pues Primo puso nota de que la improcedencia, impertinencia y términos de la presente instancia justifican, una vez más, las medidas tomadas contra este catedrático, constante ejemplo de rebeldía y mala enseñanza... El tribunal supremo, al que acudió el exrector se declaró incompetente. Se sacó a concurso su cátedra, luego a oposición, que logró un clérigo salmantino... El catedrático y penalistas republicano Luis Jiménez de Asúa asistió a aquellos penosos ejercicios con unos estudiantes, siendo detenido y desterrado a las Chafarinas, junto a Salvador Vila y Francisco de Cossío. Unamuno desde el destierro, en su libro De Fuerteventura a París, intercalaba entre la belleza de sus sonetos, las miserias del monarca y del dictador... ${ }^{30}$.

El año 1925 Primo de Rivera organiza un homenaje oficial al monarca, como desagravio implícito por el libro del novelista y político republicano Vicente Blasco Ibáñez, Alfonso XIII desenmascarado. El rector Esperabé acude con una representación -bien recibida- y continúa sus lazos con el

29. José López-Rey, Los estudiantes frente a la dictadura. Madrid, Javier Morata, 1930, cita p. 13. Véase Valentín del Arco López, «Unamuno frente a Primo de Rivera, 1923-1924», Studia historica, 4, 4 (1986), 129-179; también Emilio González López, El espíritu universitario, Madrid, Javier Morata, 1931; Antonio Gascón, Los estudiantes. Un reportaje, Madrid, Editorial Castro, s. a; $\mathrm{M}^{2}$ Fernanda Mancebo, La universidad de Valencia. De la monarquía a la república (1919-1939), Universidad de Valencia, 1994.

30. De Fuerteventura a Paris. Diario intimo de confinamiento y destierro vertido en sonetos, París, Excelsor, 1925. 
dictador, que rendirían resultados al año siguiente con la devolución del dinero que entregó Unamuno y el reconocimiento de la propiedad universitaria del edificio del colegio de Anaya. Contrapartida fue el doctorado honoris causa a favor del dictador; en claustro de 16 de junio de 1926 el rector y sólo 27 claustrales -siete de ellos en contra- a propuesta del profesor Beato Sala, acordaron la concesión «al estadista insigne que ha sabido llevar a cabo con su abnegación, con su patriotismo y talento, mediante la más suave dictadura, una obra de regeneración y altamente humanitaria...", según dijo el rector en el acto de apertura de curso e investidura. Por las calles corría una parodia de un soneto de santa Teresa con alusión al evento... ${ }^{31}$.

La lucha de los estudiantes contra la dictadura empezó aquellos años. Primo de Rivera -como todo político, y más un dictador- quiso reformar las universidades. Primero les concedió personalidad jurídica y una fingida autonomía, aunque fuera por atraerse a los claustros; creó los patronatos de las universidades y empezó a erigir colegios mayores, para controlar al alumnado. Ya en 1925 en el homenaje a Ganivet hubo disturbios -Unamuno, siempre presente, escribió una carta: «hoy en tu patria, en nuestra patria, Ángel, no puede vivir digno el que no se allane cobarde a silenciar la verdad y a no denunciar la injusticia». Pretendió el dictador atraer a los estudiantes a sus organizaciones juveniles, pero sin éxito. La Federación universitaria escolar -la FUE- se iba formando en Madrid, y en las universidades de provincias. Se preparó otro decreto-ley, la reforma universitaria del ministro Callejo de 1928 -que fue debatida en la asamblea nacional, caricatura de cortes del dictador-. Con algunas concesiones sobre asignaturas y doctorado, quiso domeñar a los estudiantes y a los docentes... El artículo 53, concedía más participación en los exámenes anuales de sus alumnos a las universidades privadas, y empezó la gran batalla de los estudiantes contra Primo de Rivera. La detención del estudiante Sbert, acaloró más aún los ánimos... Los alborotos afectaron a casi todas las universidades,

31. Valentín del Arco López, «El siglo XX: 1900-1936», p. 254-266, nota 69, en la 70 un romance de Unamuno. Esperabé - que tan duramente lo calificó en su Historia, II, p. 203-206- en 1930 publicó un folleto, Actualidad universitaria. Contestando a Unamuno, Imprenta F. Núñez, en loa de sus propias realizaciones y fastos, mientras ataca la gestión de aquél, porque no quiso poner lápida a Gil Robles o despreció a algunos salmantinos a su parecer ilustres; se opuso a la idea de una universidad hispanoamericana, hizo expediente a unas maestras o dijo que en Salamanca «no había ni mayor ni menor proporción de burros que en otra cualquiera». 
con Madrid, Barcelona, Santiago y Valencia a la cabeza; Salamanca también se levantó, en especial su facultad de medicina, que fue cerrada... Se anularon matrículas, se crearon comisarías regias para imponer el orden. Varios profesores salmantinos, encabezados por el rector Esperabé y los decanos, manifestaron su apoyo al dictador. En cambio, García Valdecasas, Wenceslao Roces y José Antón Oneca, junto a otros, discreparon, abandonaron su cátedra y se les abrió expediente ${ }^{32}$.

Unamuno, desde el exilio, clamaba en favor de los estudiantes: «Salvad a España, estudiantes, salvadla de la injusticia, de la ladronería, de la mentira, de la servilidad y, sobre todo, de la sandez. Más que otras infamias criminales está degradando a nuestro país el que le dicte tiranía ese dechado de majadería que atrae sobre él la burla del mundo entero. Salvadla, hijos míos, e iré cargado de años y de recuerdos a que me cunéis mi último sueño, mi última esperanza y a descansar en una tierra que habréis hecho hogar espiritual de Libertad, de Verdad y de Justicia ${ }^{33}$ ". Al fin hubo de ceder el dictador en vísperas de su caída. Volvió Unamuno a Salamanca el 13 de febrero de 1930, donde recibió una acogida apoteósica; muchos quieren que sea rector, pero Esperabé se resiste a dimitir: al fin fue nombrado Ramos Loscertales, también de tendencia muy conservadora... El jueves primero de mayo se tributa a don Miguel un multitudinario recibimiento en la estación del norte madrileña, aclamado por numerosos estudiantes, contra los que cargó la policía; da una conferencia en el ateneo, unos días después habla en la universidad central, donde hubo tiros y algún muerto. La policía le obliga a tornar a Salamanca... La situación siguió agitada durante los gobiernos provisionales del general Berenguer y del almirante Aznar hasta la llegada de la república. Siguieron los alborotos: el 4 de abril de 1931 los escolares salmantinos destrozan el retrato de Alfonso XIII del paraninfo...

32. E. López-Rey, Los estudiantes, escritos del rector Esperabé y de los discrepantes, p. 171-172, 176-177, 233; el manifiesto de los cien, 175-176; Valentín del Arco López, «El siglo XX: 1900-1936", p. 268-286. Enrique Esperabé escribiría un folleto de exaltación al régimen -mataron a su hijo en el Madrid republicano -: La guerra de reconquista española que ha salvado a España del comunismo - El glorioso ejército nacional y los mártires de la patria, Madrid, R. de San Martín, 1939; no obstante, años después en una síntesis análoga, Los partidos políticos en España...(1868-1950), Madrid, 1951, en su loa final a Salamanca nos recuerda que en ella «se encerró y concentró Unamuno con su poderoso intelecto, por expresa voluntad suya, para glosarla con su sugestivo e inmutable estilon, p. 341.

33. E. López-Rey, Los estudiantes, p. 143-146 la carta de Unamuno, junto a otra a los padres, 146-152; también Gascó, p. 65-72. 


\section{REPÚBLICA Y GUERRA CIVIL}

Llega la república y Unamuno escribe varios artículos, llenos de fe en el porvenir. Hace un repaso histórico en que ataca al monarca y al dictador: es optimista, no hay peligro alguno de comunismo, ni de fajismo -él escribió siempre así fascismo-, ni riesgo de una reacción clerical, pues hay mayor cultura y educación cívica en el pucblo. Habrá que plantear si es una república federal o unitaria, los problemas del campo, de la hacienda pública... Junto a Marañón, Ortega y Pérez de Ayala, entre otros profesores, espera remedio de la caída de Alfonso XIII, con quien tanto se había enfrentado-«los comuneros de hoy, se han alzado contra él»-. Unamuno es elegido concejal, es nombrado alcalde honorario, presidente del consejo de instrucción pública, rector, luego diputado. Intervendría varias veces en las primeras cortes sobre la lengua vasca y catalana y sobre el estatuto de Cataluña o sobre la libertad de enseñanza. Aunque luego empieza a mostrar desconfianza, se retira del congreso al no presentarse a la segunda legislatura... El último día de septiembre de 1932 había dado su última lección en el paraninfo, en presencia de Alcalá Zamora, y de nuevo pidió a los estudiantes que salvasen a España... ${ }^{34}$.

En las vísperas del alzamiento su preocupación aumenta: le escribe a Enrique Díez-Canedo, para disculparse por no acudir a un congreso en Argentina: «Parece que está de Dios que yo no logre "Ultramarinarme". ¡Cómo ha de ser...! Como no cambie esto...». Había ido a Inglaterra con su hijo por el doctorado honoris causa de Oxford. "Y temía -como sigo temiendo-que las cosas de esta nuestra España me obligaran a restituirme a ella y a mi familia y hogar». Volvió por la enfermedad y muerte de su hija, su salud era mala. "Pero lo que sobre todo ahora me retiene es el estado de la cosa pública (res publica) en esta nuestra España, sobre la que veo cernerse una catástrofe si la Providencia o el Hado o lo que sea no lo remedia» 35.

Salamanca fue centro de los rebeldes, con el general Franco a la cabeza, que concentró todos los poderes. Se formó una junta y durante años -con Burgos- fue sede del gobierno. Unamuno, concejal del nuevo ayuntamiento,

34. Salcedo, Vida, p. 320-422 hasta su muerte; sus artículos en El Sol, 13 a 15 de mayo de 1931, Miguel de Unamuno, República española y España republicana (1931-1936). Artículos no recogidos en las obras completas, edición de V. González Martín, Almar, Salamanca, 1979, p. 73-84; en estas páginas puede bucearse su distanciamiento, «Profecías» o «La revolución de dentro", 218-220 y 246-249.

35. Carta de 10 de junio de 1936, De Max Aub a Unamuno (Dos homenajes), Fundación Max Aub, Segorbe, 1998, p. 23-25. 
declara el 26 de julio la necesidad de salvar la civilización occidental, la civilización cristiana. En sus declaraciones a la prensa internacional o en sus artículos en periódicos locales apoya el alzamiento militar contra el frente popular que había ganado las elecciones de febrero del 36 . Fue destituido por la república legítima y repuesto por el general Cabanellas. Otros numerosos catedráticos de Salamanca se sintieron cerca del nuevo régimen -Madruga, Ramos Loscertales, González Oliveros, Torres López, Sánchez Tejerina, Serrano, Beato Sala...-. La universidad colaboró en múltiples actos de propaganda y apoyo, con sus edificios, en la sanidad de guerra o con ideología... El 26 de septiembre aprobaba un mensaje a las universidades y academias del mundo acerca de la guerra civil -redactado por Teodoro Andrés Marcos y Ramos Loscertales-, unos días antes de la pastoral colectiva de los obispos que respaldaba la «cruzada» de Franco ${ }^{36}$. El paraninfo albergó homenajes a José Antonio, el fundador de Falange, o a Menéndez Pelayo, a Calvo Sotelo...; reuniones de las academias o de los rectores franquistas...

Unamuno en sus últimos meses garrapateaba unas páginas a lápiz sobre la guerra civil. En la primera hizo una exacta profecía: al decirle que habían asesinado a Rodríguez-Fornos, catedrático de medicina en Valencia -lo que no era cierto-, respondió, "y a quién de izquierda fusilarán en compensación al entrar en Valencia los... negri-rojos? a Peset?» 37. Reúne notas sobre la terrible tragedia que tal vez pensó convertir en un futuro ensayo. Rezuma pesimismo: «Desesperación resignada... Se pierde la conciencia de humanidad». «Entre los hunos y los otros están descuartizando a España». «El pueblo español se entrega al suicidio. Pero como le retiene el instinto animal de vivir -y reproducirse- se entrega a estupidizarse, al opio o al alcohol. El goce de morir matando». "Ahora volverán Chateaubriand y De Maistre... Reaparece el Ángel Exterminador».

36. Tomás Pérez Delgado, La universidad de Salamanca, I, p. 287-320; Tomás Pérez Delgado y Antonio Fuentes Labrador, «De rebeldes y cruzados», Studia historica. Historia contemporánea, 4, 4, 1986, 235-266; A. Fuentes Labrador, $M^{\mathrm{a}}$ A. Sampedro, F. Corrionero, $\mathrm{M}^{\mathrm{a}} \mathrm{J}$. Velasco, «Apoyo institucional en un centro de poder: la universidad de Salamanca durante la guerra civil. Un modelo de comportamiento", La universidad española bajo el régimen de Franco. Actas del congreso celebrado en Zaragoza, 8-11 nov. 1989, Zaragoza, 1991, 257-282; Ramón Hernández, "La cátedra "Francisco de Vitoria" de la universidad de Salamanca», Actas del IV seminario de historia de la filosofia española, 12-13, $1987,335-383$.

37. Del resentimento trágico de la vida. Notas sobre la revolución y la guerra civil españolas, nota de M. de Unamuno Adarraga, prólogo de M. Quiroga de Unamuno, estudio de Carlos Feal, Madrid, Alianza tres, 1991, p. 19. Véase Proceso a Juan Peset Aleixandre, edición de Ma Fernanda Mancebo, Marc Baldó y Salvador Albiñana, Universitat de Valencia, 2001. 
Su última intervención la haría en el solemne acto académico del día de la raza, el 12 de octubre de 1936, en el paraninfo de Salamanca. Presidía la sesión en representación de Franco, con numerosas autoridades. Llegaron la esposa del general y el cardenal Plá y Deniel, y hubo que colocarlos en lugares preferentes. Hablaron Ramos Loscertales, el dominico Vicente Beltrán de Heredia, Francisco Maldonado y José Pemán. Al final tomó la palabra el viejo rector:

Dije que no quería hablar, porque me conozco; pero se me ha tirado de la lengua y debo hacerlo. Se ha hablado aquí de guerra internacional en defensa de la civilización cristiana; yo mismo lo he hecho otras veces. Pero no, la nuestra es sólo una guerra incivil. Nací arrullado por una guerra civil y sé lo que me digo. Vencer no es convencer, sobre todo, y no puede convencer el odio que no deja lugar para la compasión; el odio a la inteligencia que es crítica y diferenciadora, inquisitiva, mas no de inquisición. Se ha hablado también de los catalanes y los vascos llamándoles la anti-España; pues bien, con la misma razón pueden ellos decir otro tanto. Y aquí está el señor obispo catalán para enseñaros la doctrina cristiana que no queréis conocer, y yo que soy vasco llevo toda mi vida enseñándoos la lengua española que no sabéis. Ese es el imperio, el de la lengua española, y no... ${ }^{38}$.

Lo interrumpe y le contesta Millán Astray -desde un extremo de la presidencia- sobre los motivos del levantamiento; vuelve a hablar Unamuno, el general termina con gritos de «Mueran los intelectuales» y « $i$ Viva la muerte!». Unamuno inicia la réplica, habla el general, estalla el escándalo... Es sacado de la sala por la mujer de Franco, entre amenazas y voces. Por la tarde, ya rehecho, acudió al casino, donde fue abucheado con hostilidad; su hijo lo conduce a casa... Fue depuesto de inmediato de la concejalía y del rectorado. A instancia del decano de letras el claustro pidió su cese como rector perpetuo el día 14; el 22 sendos decretos de Franco lo cesan y

38. La reconstrucción de Emilio Salcedo, Vida, p. 413-422; hay otras versiones L. González Egido, Agonizar en Salamanca. Unamuno, julio-diciembre 1936, Madrid, Alianza, 1986; Crónica de la guerra española, 48, editorial Codex, Buenos Aires, véase Santos Martínez Sáura, Espina, Lorca, Unamuno y Valle Inclán en la política de su tiempo, Madrid, Libertarias/Prodhuf, 1995, p. 219-221, en 222-229 reproduce un escrito posterior de Unamuno -editado por Jean y Jérôme Tharaud, Cruelle Espagne y dos cartas últimas, por Bergamín en Historia 16, 1976. Las ideas de su intervención estaban ya en germen en "La fiesta de la raza", u otros contra el fascismo, su artículo con una svástica dibujada como título; así como otros en República española, p. 169-175, 273-281, contra anarquistas también; en octubre de 1934 ya escribió: «Estamos viviendo en una guerra civil incivil. ¿Pasión? Más bien insensatez. Y hasta locura. Una verdadera epidemia. Y más que de locura de demencia...», p. 338. 
nombran a Esteban Madruga, que había sido su vicerrector. Unamuno se recluye en casa, vigilado hasta su muerte dos meses después...

En aquellas notas suyas se haría eco de aquel momento que había vivido: " "Viva la muerte!" grita Millán Astray. Lo que quiere decir "muera la vida"”. "Servicio, obediencia. Para saber obedecer hay que tener inteligencia, interpretar el mandato... Dos apolíticas: no hay Estado, anarquismo libertario; no hay más que Estado, fajismo y comunismo... Vencer no es convencer; conquistar no es convertir». "Me destituye Madrid; me restituye Burgos. Y luego me destituyen mis compañeros. Los motejados de intelectuales les estorban tanto a los hunos como a los otros. Si no les fusilan los fascistas les fusilarán los marxistas. A quien se le ocurre ponerse de espectador entre dos bandas contendientes sin tomar partido ni por una o ni por otra?». "Odio a la inteligencia? O no más bien miedo a ella?». "Viva la muerte». «Imperio! Empresa imperial. Italia Abisinia. Nosotros el desierto del Sahara y ponerlo en el mapa de negro y rojo. Y si no un Sahara espiritual, la escolástica española del XVII". " "Muera la intelectualidad y viva la muerte", Millán Astray ». "Qué estúpida retórica! Arriba España! Y creen que han dicho algo. Sí ¡viva Virgen! O el ¡viva la muerte! de Millán Astray» ${ }^{39}$.

Moriría el 31 de diciembre, y su nombre quedaría ligado, inseparable de la universidad de Salamanca. Sus restos, sus huellas, permanecen, como él pidió años antes al final de la Oda a Salamanca «cuando me vaya, entre tus piedras guarda, tú, mi recuerdo...».

39. Citas de El resentimiento, p. 35, 39-49, 53 y 55, deplora asesinatos de los republicanos y de los nacionales: "Pobre Deán de Toledo Polo Benito! Pobre Arturo Pérez Martín! Pobre Prieto Carrasco! Pobre Beúnza! pobre teniente Castillo! pobre Calvo Sotelo! Pobre...»; al final -26 de noviembre-, un discípulo suyo, apresado en Salamanca: «En Granada han fusilado, los falangistas al pobre Salvador Vila», 43 y 57. 